\title{
Pathogenicity and Aggressiveness of Three Alternaria spp. on Potato Foliage in the U.S. Northwest
}

Lydia S. Tymon, Thomas F. Cummings, and Dennis A. Johnson, Department of Plant Pathology, Washington State University, Pullman 99164

\begin{abstract}
Tymon, L. S., Cummings, T. F., and Johnson, D. A. 2016. Pathogenicity and aggressiveness of three Alternaria spp. on potato foliage in the U.S. Northwest. Plant Dis. 100:797-801.

Alternaria spp. were collected from potato foliage showing symptoms of early blight and brown spot in the Columbia Basin, WA and Bonners Ferry and Rupert, ID between 2009 and 2011. The aggressiveness of three Alternaria spp. on potato was quantified on nonwounded and wounded detached leaves of 'Russet Norkotah' potato; wounded detached leaves of 'Alturas', 'Ranger Russet', 'Russet Burbank', and 'Umatilla Russet'; and whole plants of Russet Norkotah. Mean infection frequencies (MIF) and area under the lesion expansion curve (AULEC) were significantly greater for Alternaria solani ( $P=0.0072$ and 0.0002 , respectively) than for $A$. arborescens or A. arbusti on nonwounded leaves. Wounding of tissue significantly increased MIF and AULEC for A. arbusti $(P=0.008$ and

0.0047, respectively) and AULEC for A. arborescens $(P=0.01)$ relative to nonwounded tissue. AULEC did not differ significantly among the three Alternaria spp. when inoculated onto wounded foliage of whole plants $(P=$ 0.34 ); the AULEC of whole plants was positively and significantly correlated with AULEC on detached leaves $(P=0.03)$. Umatilla Russet was the most susceptible and Russet Burbank was the least susceptible based on MIF and AULEC for all three pathogen species. Results indicate that A. solani was the more aggressive pathogen of potato in the Columbia Basin, because both $A$. arborescens and $A$. arbusti require wounds and A. arbusti lesions do not expand significantly in comparison with $A$. solani or $A$. arborescens following inoculation.
\end{abstract}

Alternaria solani Sorauer, which causes early blight of potato, was first described in 1882 by Ellis and Martin (1882). Infection results in tan-colored lesions that are often surrounded by a chlorotic halo due to the presence of fungal metabolites (Rotem 1994). A. alternata (Fr.) Keissl. causes brown spot of potato and lesions are smaller and darker compared with A. solani (Kirk and Wharton 2012). A. alternata was isolated from potato leaf lesions in 1984 and Koch's postulates were fulfilled on intact, detached potato leaves (Droby et al. 1984). Inoculum concentration and disease incidence were positively correlated.

Potato early blight and brown spot are diseases of senescing tissue (Douglas and Pavek 1972; Lawrence et al. 2013; MacKenzie 1981; Rotem 1994; Shtienberg et al. 1995). Older leaves of potato are more susceptible to infection by $A$. solani and A. alternata than younger leaves (Droby et al. 1984; Dita Rodriguez et al. 2006). However, young leaves are also susceptible, particularly as the growing season progresses (Kirk and Wharton 2012; Wharton and Kirk 2007). Susceptibility of hosts is also dependent on overall plant vigor. Plants under drought stress or less than optimal nutrition regimes are more susceptible to infection, most likely due to the premature senescence of foliage (Blachinski et al. 1996; Rotem 1994).

Traditional management strategies for A. solani and A. alternata include the use of moderately resistant cultivars and fungicides in an integrated management strategy (Fry 2007). Resistance is determined by the ability of the plant to inhibit lesion development and expansion and has been directly correlated with cultivar maturity. However, no cultivar is known to be completely resistant to infection (Douglas and Pavek 1972).

Corresponding author: L. Tymon; E-mail: lydia.tymon@wsu.edu

PPNS number 0695, Department of Plant Pathology, College of Agricultural, Human, and Natural Resource Sciences Agricultural Research Center, Hatch Project number WNPO 0678, Washington State University, Pullman 991646430.

Accepted for publication 6 November 2015 .

http://dx.doi.org/10.1094/PDIS-08-15-0942-RE

C 2016 The American Phytopathological Society
Although a number of Alternaria spp. have been identified as pathogens on potato internationally (Ardestani et al. 2010; Rodrigues et al. 2010; van der Waals et al. 2011), only A. solani and A. alternata have been described as pathogens in the United States.

In the U.S. Northwest, $A$. solani has been the dominant pathogen; however, A. alternata is increasingly affecting American potato production (Nolte 2008).

Species delimitation within the Alternaria spp. is challenging due to similarities in conidial morphology and morphological plasticity in response to environmental conditions, particularly within species with small conidia (Rotem 1994; Simmons 2007). This poses an issue with identification. Morphospecies classifications, based on morphological characteristics (Simmons 1992), often agree with clade structure based on molecular systematics (Hong et al. 2005; Peever et al. 2004; Pryor and Gilbertson 2000). However, some studies have shown that morphospecies classifications are not always congruent with molecular systematic analyses (Andrew et al. 2009; Lawrence et al. 2013; Peever et al. 2004).

A survey of Alternaria spp. that colonize potato in the U.S. Northwest was conducted between 2009 and 2011 (Tymon and Johnson 2011). Isolates of Alternaria spp. were collected from early blight and brown spot lesions on potato. Four morphologically and genetically distinct Alternaria spp. were isolated: A. solani, A. alternata/ tenuissima, A. arborescens, and A. arbusti, which has not been described on potato (Tymon et al. 2015). Previous studies of Alternaria spp. on potato have identified A. alternata as the predominate small-spored Alternaria sp. and have characterized its pathogenicity (Droby et al. 1984). In this survey, A. arborescens was isolated more frequently than $A$. alternata. Because previous work has not been conducted on the aggressiveness of $A$. arborescens or A. arbusti on potato, these two fungi were the focus of this study. Additionally, a preliminary pathogenicity assay suggested that $A$. arborescens was more aggressive than $A$. alternata (data not shown). Therefore, the objectives of this study were to (i) quantify and compare the aggressiveness of $A$. arborescens and $A$. arbusti isolates sampled from the U.S. Northwest on potato to A. solani, which is the dominant pathogen on potato; and (ii) quantify and compare the aggressiveness of A. arborescens and A. arbusti to A. solani on different potato cultivars, including 'Alturas', 'Russet Burbank', 'Ranger Russet', 'Umatilla Russet', and 'Russet Norkotah'. 


\section{Materials and Methods}

Collection, preservation, and identification of isolates. Potato foliage with early-blight-type lesions was collected from potato fields in the Columbia Basin of Washington, in Rupert, ID, and near Bonner's Ferry in north Idaho in 2009 to 2011. In total, 940 smallspored Alternaria spp. and 600 large-spored isolates (putatively A. solani) were collected. Foliage was placed in plastic bags, sealed, and transported to a laboratory in Pullman, WA. Leaves were stored at $4^{\circ} \mathrm{C}$ until processed. Potato leaflets with lesions were surface disinfested by dipping in $70 \%$ ethanol for 3 to $5 \mathrm{~s}$. Leaflets were blotted with paper towel and air dried. One to three lesions per leaf (one lesion per leaflet) were sampled. Lesion margins were excised and plated on a modified potato dextrose agar (mPDA; Difco Bactoagar at $20 \mathrm{~g} / \mathrm{liter}$, Difco PDA at $1 \mathrm{~g} / \mathrm{liter}$, and $95 \%$ ethanol at $6 \mathrm{ml} / \mathrm{liter}$ ). Singleconidial isolates were obtained from single lesions from single leaflets and grown on mPDA at 21 to $23^{\circ} \mathrm{C}$ under constant light. Isolates were grown on mPDA for 7 to 10 days and stored on filter paper squares. Squares were placed in autoclaved coin envelopes and maintained at room temperature for future inoculation experiments.

Isolates were identified using morphological characteristics as well as through sequencing of glyceraldehyde 3 phosphate and Scar marker OPA 1-3 (Tymon et al. 2015).

Plant growth. Seed potato pieces were removed from cool storage and warmed to room temperature for $24 \mathrm{~h}$ prior to planting. Approximately three seed pieces were cut from each potato. One seed piece was planted approximately $6 \mathrm{~cm}$ deep into a round, plastic container (15.3 cm in diameter) filled with Sunshine number 1 (Sun Gro Horticulture, Agawam, MA) soilless planting media. Greenhouse temperatures were approximately $21^{\circ} \mathrm{C}$ during the day and $10^{\circ} \mathrm{C}$ at night. The photoperiod was at least $14 \mathrm{~h}$ from natural light. Russet Norkotah plants were maintained in the greenhouse during spring and summer for approximately 2.5 months after emergence in July and August 2012 and 2013 prior to leaf excision for detached-leaf assays. Alturas, Russet Burbank, Ranger Russet, Umatilla Russet, and Russet Norkotah potato plants (Table 1) were maintained for approximately 3.5 months postemergence in July through September 2012 before inoculation.

Inoculum preparation. Two isolates of $A$. arbusti, two of $A$. arborescens, and one of $A$. solani were selected for inoculation from 200 isolates of Alternaria that were prescreened for pathogenicity on excised leaves of Russet Norkotah potato. The five isolates (Table 2) were pathogenic and were used to inoculate detached leaves and whole plants. The isolate of $A$. solani was used as a control. Inoculum was prepared by culturing single-spore isolates on mPDA for 13 days under 24-h lights at room temperature. Plates were gently scraped using a scalpel and spores were suspended in sterilized distilled $\mathrm{H}_{2} \mathrm{O}$. The suspension was filtered through three layers of cheesecloth and inoculum was standardized to $10^{3}$ spores $/ \mathrm{ml}$ using a hemocytometer.

Detached-leaf assay. Potato leaflets from detached compound leaves were either not wounded or were wounded using a sterilized scalpel (one wound per leaflet). Wounds were approximately $10 \mathrm{~mm}$ long and the width of the blade edge. Excised leaves were sprayed with distilled water until runoff and then placed on moistened, clean paper towels on fiberglass screens in 5.5-cm-deep Pyrex baking pans. In all, 200 Alternaria isolates were used to prescreen for pathogenicity on potato. Of these 200 isolates, 5 isolates ( 2 isolates of A. arbusti, 2 of $A$. arborescens, and 1 of $A$. solani; Table 2) were selected for additional inoculation assays. The two $A$. arborescens isolates were selected based on mean infection frequency. Isolate aa10_312 exhibited moderate pathogenicity on nonwounded tissue and aa10_328 exhibited low pathogenicity on nonwounded tissue (data not shown). Spore suspension $(20 \mu \mathrm{l})$ was applied to a $1-\mathrm{cm}^{2}$ filter paper, which was placed so that conidia were in direct contact with either nonwounded or wounded tissue of the leaflets. Only one isolate was inoculated onto five leaflets (subsamples) per compound leaf, where leaflets remained attached to leaf. Whole leaves were placed into Pyrex pans and sealed into plastic bags. Pans were maintained under 24 -h lights at 21 to $23^{\circ} \mathrm{C}$ on a laboratory benchtop. Filter paper squares were removed after $48 \mathrm{~h}$ and lesions were measured at 3,5 , and 7 days postinoculation.

Laboratory space was limited and did not allow for replications of isolates within each trial. Therefore, repeated trials were used as replications, with the first and second trials 2 weeks apart in July 2012 and the third trial in August 2013, giving three replications of five subsamples (leaflets) for each of the five isolates.

Whole-plant assay. Pathogenicity of the five selected isolates used in the detached-leaf assays (Table 2) was also tested on whole plants to validate the inoculated detached-leaf assays. Norkotah potato plants were grown in a greenhouse environment for 2 months postemergence in July and August 2013 at 12-h mean temperatures of $21^{\circ} \mathrm{C}$ during the day and $10^{\circ} \mathrm{C}$ at night. A spore suspension for each isolate was prepared and standardized to $10^{3}$ spores $/ \mathrm{ml}$ as above. Potato leaflets were abraded using a heavy-duty scouring pad (3M, St. Paul, MN). Wounded leaflets were sprayed with distilled water until runoff using a hand sprayer. Filter paper squares were dipped into the spore suspension and then placed on the wounded leaf. Each isolate was inoculated onto one leaflet on one leaf on each of four plants. Each of the four plants was a replicate in a randomized complete block design, where the plant was the block. Whole plants were sealed in clear plastic bags. Plants were maintained at approximately 21 to $23^{\circ} \mathrm{C}$ for 7 days under constant light. Bags and the filter paper were removed after $48 \mathrm{~h}$. Lesions were measured at 3,5 , and 7 days postinoculation. The wholeplant assay was repeated a week later.

Experimental design and analysis. Infection frequency for each replicate was calculated as the mean incidence of infection of the five subsamples. Lesion area was calculated from lesion diameter measurements diameter $1\left(d_{l}\right)$ and diameter $2\left(d_{2}\right)$ using the formula $\mathrm{A}=d_{1} \times$ $d_{2}$, where $d_{1}$ and $d_{2}$ were perpendicular to each other. Mean lesion area of the five subsamples was then used to calculate the area under the lesion expansion curve (AULEC), which integrates lesion area over time (Shaner and Finney 1977). AULEC was calculated as follows:

$$
\text { AULEC }=\sum_{i=1}^{n}\left[\frac{\left(y_{i}-y_{i+1}\right)}{2}\right]\left(t_{i+1}-t_{i}\right)
$$

where $y_{i}$ is lesion area in square millimeters at time $t_{i}$. Mean infection frequency (MIF) and AULEC were measures of pathogen aggressiveness.

Table 2. Isolate, collection year, Alternaria spp., and collection area of the five isolates selected for pathogenicity and aggressiveness assays on detached leaves and whole plants ${ }^{\mathrm{a}}$

\begin{tabular}{lcll}
\hline Isolate & Year collected & \multicolumn{1}{c}{ Species } & Collection area \\
\hline aa09_157 & 2009 & Alternaria arbusti & Bonners Ferry, ID \\
aa11_80 & 2011 & A. arbusti & Bonners Ferry, ID \\
aa10_312 & 2010 & A. arborescens & Rupert, ID \\
aa10_328 & 2010 & A. arborescens & Rupert, ID \\
as10_315 & 2010 & A. solani & Rupert, ID \\
\hline
\end{tabular}

${ }^{a}$ Isolates were selected based on preliminary pathogenicity assays.

Table 1. Maturity and early blight resistance of five potato cultivars

\begin{tabular}{llll}
\hline Cultivar & \multicolumn{1}{c}{ Maturity } & Early blight resistance & Reference \\
\hline Alturas & Late & Resistance & Novy et al. 2003 \\
Russet Norkotah & Early to medium & Susceptible & Johanson et al. 1988 \\
Ranger Russet & Late & Moderately resistant & Pavek et al. 1992 \\
Russet Burbank & Late to very late & None noted & Rykbost et al. 1990 \\
Umatilla Russet & Medium to late & Moderately susceptible & Mosley et al. 2000 \\
\hline
\end{tabular}


A treatment was an inoculation by a species on wounded or nonwounded potato leaflets. Data for MIF and AULEC were analyzed by analysis of variance using PROC GLM in SAS statistical software (ver. 9.2; SAS Institute Inc., Cary NC). Trials were used as replications for detached-leaf assays. For the whole-plant assays, plants were used for replications of the treatments (isolates) and repeated. No significant differences in MIF or AULEC were observed between isolates within species among the three trials. Therefore, isolates within a species were combined.

AULEC of Alternaria isolates on detached leaves were regressed on the AULEC of isolates on whole plants. Regression compared AULEC from the third trial on detached leaves to AULEC on whole-plant trials because the detached leaves were excised from plants of identical age, seed source, and location as the wholeplants trial.

\section{Results}

Detached-leaf assays on Russet Norkotah. Mean infection frequency on nonwounded tissue was significantly greater $(P<0.05)$ for $A$. solani than for $A$. arborescens and A. arbusti in all three trials (Table 3). A significant interaction $(P<0.05)$ was observed between species and wounding, which was due to an increased MIF on wounded leaflets inoculated with $A$. arbusti. A significant interaction

Table 3. Mean infection frequency on nonwounded and wounded detached leaves of Russet Norkotah inoculated with three Alternaria spp. in three trials ${ }^{\mathrm{a}}$

\begin{tabular}{lccc}
\hline Alternaria spp. & Nonwounded & Wounded & $\boldsymbol{P}$ value \\
\hline Alternaria arborescens & $0.83 \mathrm{a}$ & $0.7 \mathrm{a}$ & 0.09 \\
A. arbusti & $0.33 \mathrm{a}^{*}$ & $0.6 \mathrm{a}$ & 0.008 \\
A. solani & $0.08 \mathrm{~b}$ & $1.0 \mathrm{a}$ & 0.38 \\
$P$ value & 0.0072 & 0.24 & $\ldots$ \\
\hline
\end{tabular}

a Values with the same letters within a column are not significantly different at $P \geq 0.05$. An asterisk (*) indicates that values are significantly different than the wounded at $P<0.05$.

Table 4. Area under the lesion expansion curve on nonwounded and wounded Russet Norkotah leaves in two trials and wounded whole Russet Norkotah plants inoculated with Alternaria spp. in two trials ${ }^{\mathrm{a}}$

\begin{tabular}{lccccc}
\hline & \multicolumn{3}{c}{ Detached-leaf assay } & & Whole plant \\
\cline { 2 - 4 } Alternaria spp. & Nonwounded & Wounded & $\boldsymbol{P}$ value & & Wounded \\
\hline Alternaria arborescens & $50 \mathrm{a}^{*}$ & $211 \mathrm{a}$ & 0.01 & & $345 \mathrm{a}$ \\
A. arbusti & $8 \mathrm{a} \mathrm{a}^{*}$ & $64 \mathrm{a}$ & 0.0047 & & $294 \mathrm{a}$ \\
A. solani & $716 \mathrm{~b}$ & $499 \mathrm{~b}$ & 0.55 & & $404 \mathrm{a}$ \\
$P$ value & 0.0002 & 0.001 & $\ldots$ & \\
\hline
\end{tabular}

${ }^{a}$ Values with the same letters within a column are not significantly different at $P \geq 0.05$. An asterisk (*) indicates that values are significantly different than the wounded at $P<0.05$. was not observed $(P>0.05)$ between the MIF and wounding of tissue inoculated with $A$. arborescens or A. solani.

AULEC of trial 1 was significantly greater than for trials 2 and 3. However, in all three trials, AULEC was significantly greater when tissues were inoculated with A. solani than with A. arborescens or $A$. arbusti regardless of wounding and did not significantly differ between $A$. arborescens and $A$. arbusti (Table 4). A significant interaction was observed $(P<0.05)$ between species and wounding, which was due to an increased AULEC on wounded than nonwounded leaflets inoculated with $A$. arborescens and A. arbusti.

Whole-plant assay. AULEC did not differ significantly among the three Alternaria spp. on whole plants (Table 4). However, AULEC of isolates on leaves of whole plants significantly increased as AULEC on detached leaves increased when analysis was conducted on the third trial $(P=0.03$; Fig. 1$)$. When all trials were combined, an association was found between AULEC values obtained from whole plants and detached leaves $(P=0.07)$ (data not shown). $A$. solani was the most aggressive on whole plants and A. arbusti isolates were the least aggressive.

Detached-leaf assay on Russet potato cultivars. The MIF was significantly greater $(P<0.05)$ on Umatilla Russet than Russet Burbank when inoculated with $A$. arborescens or A. arbusti (Table 5); mean infection frequency did not differ significantly on Umatilla Russet, Ranger Russet, Russet Norkotah, and Alturas when inoculated with A. arborescens. A significant difference in MIF was not observed between Umatilla Russet and Ranger Russet when inoculated with $A$. arbusti but MIF on Umatilla Russet was significantly greater than on Russet Norkotah and Alturas. A significant difference was not observed among cultivars when inoculated with A. solani. Mean infection frequency on Russet Norkotah and Russet Burbank was significantly greater when inoculated with $A$. solani than A. arborescens or $A$. arbusti and no significant difference was observed among the species of Alternaria on Umatilla, Ranger, or Alturas.

AULEC of Alternaria spp. varied significantly among potato cultivars (Table 6). AULEC did not differ significantly among cultivars when inoculated with $A$. arborescens but was significantly greater $(P<0.05)$ on Umatilla Russet than on Alturas and Russet Burbank when inoculated with $A$. solani or A. arbusti. AULEC was significantly greater on leaflets inoculated with $A$. solani than with A. arborescens or A. arbusti on each of the cultivars except Alturas. A significant difference in AULEC was not observed when Umatilla Russet, Ranger Russet, Russet Norkotah, or Russet Burbank was inoculated with $A$. arborescens or A. arbusti.

\section{Discussion}

A. solani was the most aggressive of the three Alternaria spp. tested. When tissue was wounded, MIF and AULEC for A. arborescens and $A$. arbusti increased significantly. Thus, wounding of plant tissue is an important factor for severe disease symptoms to develop. The importance of wounding has been demonstrated with Alternaria

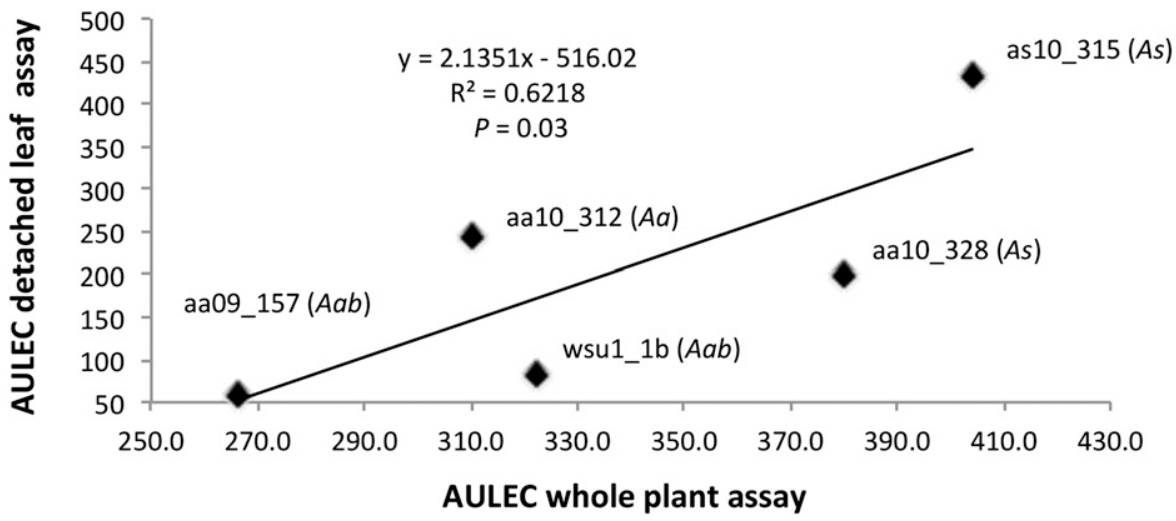

Fig. 1. Third trial regression line for area under the lesion expansion curve (AULEC) of Alternaria solani (As), A. arborescens (Aa), and A. arbusti (Aab) inoculated on detached Russet Norkotah leaves to the AULEC of isolates inoculated on whole Russet Norkotah plants. 
spp. infection on other crops. On Amaranth hybridus, Alternaria tenuissima infection on wounded leaves increased symptom development (Blodgett and Swart 2002) and, on blueberry, a higher incidence of Alternaria spp. infection occurred on berries with stem scars (Cappellini and Ceponis 1977). Wounding of potato leaves in commercial fields occurs frequently through wind carrying soil particles, insects, windburn, or machinery. In the Columbia Basin of Washington, dust storms frequently occur (Sharratt and Lauer 2006) and damage to potato foliage is not uncommon. Aggressiveness of $A$. solani did not increase on wounded tissue as it did for $A$. arborescens and $A$. arbusti because wounds may not be necessary for severe infection. Lesions caused by foliar pathogens such as A. solani or Colletotrichum coccodes could provide additional openings into host tissue, where $A$. arborescens and A. arbust $i$ then act as secondary invaders (Rotem 1994; Tymon et al. 2015).

AULEC was greater on leaves inoculated with A. arborescens than with $A$. arbusti, which may be a result of toxin production. A. arborescens as well as A. solani produce nonhost and hostspecific toxins (Rotem 1994). A. arborescens produces high levels of pectin methyl lyase, which break down the waxy cuticles; tenuazonic acid, which prevents the synthesis of proteins; and tentoxin, which inhibits photophosphorylation (Rotem 1994; Thomma 2003). In contrast, A. arbusti clusters within the infectoria clade (Lawrence et al. 2013). Host-specific toxin production is not known to occur by members of the A. infectoria clade (Andersen and Thrane 1996; Logrieco et al. 1990) although it is suspected that phytotoxic metabolites are produced by some members (Kumar and Rao 1979). Disease establishment does not require nonhost-specific and host-specific toxins. However, they do increase disease symptoms (Fry 2007) and are thought to facilitate colonization by killing cells prior to fungal invasion (Kumar and Rao 1979). Additionally, the lack of significance observed for AULEC between A. arborescens and $A$. arbusti on nonwounded leaves of Russet Norkotah contrasted with the significance on wounded leaves illustrates the influence that host defenses of intact leaves have on overall aggressiveness of Alternaria spp. (Olanya et al. 2009).

Resistance is directly associated with cultivar maturity (Boiteux et al. 1995; Douglas and Pavek 1972; Pelletier and Fry 1989). Cultivars that mature early, such as 'Norchip', tend to be more susceptible due to earlier senescence than late-maturing cultivars (Johanson and Thurston 1990; Pelletier and Fry 1989). However, some earlymaturing cultivars do exhibit early blight resistance (Boiteux et al.

Table 5. Mean infection frequency on wounded leaves of five potato cultivars inoculated with three Alternaria spp. ${ }^{\mathrm{a}}$

\begin{tabular}{llllc}
\hline Cultivar & Alternaria arborescens & A. arbusti & A. solani & $\boldsymbol{P}$ value \\
\hline Umatilla Russet & $0.6 \mathrm{a}$ & $0.8 \mathrm{a}$ & $1 \mathrm{a}$ & 0.2432 \\
Ranger Russet & $0.4 \mathrm{ab}$ & $0.5 \mathrm{ab}$ & $1 \mathrm{a}$ & 0.281 \\
Norkotah Russet & $0.3 \mathrm{ab} *$ & $0.3 \mathrm{bc} *$ & $0.9 \mathrm{a}$ & 0.0188 \\
Russet Alturas & $0.2 \mathrm{ab}$ & $0.1 \mathrm{bc}$ & $0.7 \mathrm{a}$ & 0.054 \\
Russet Burbank & $0 \mathrm{~b}^{*}$ & $0 \mathrm{c}^{*}$ & $0.8 \mathrm{a}$ & $<0.001$ \\
$P$ value & 0.11 & 0.0052 & 0.35 & $\ldots$ \\
\hline
\end{tabular}

${ }^{a}$ Values with the same letters within a column are not significantly different at $P \geq 0.05$. An asterisk (*) indicates that values are significantly different than for A. solani (across a row) at $P<0.05$.
1995). In this study, a significant cultivar effect was observed on fully expanded and green, excised leaves. All three species of Alternaria were most aggressive on Umatilla Russet and least aggressive on Russet Burbank. A comparison of these two cultivars should be made in a field study to confirm these results. Regardless, the decreased susceptibility of certain potato cultivars could be exploited to reduce the number of fungicide applications, which are currently the common management strategy in the Columbia Basin.

AULEC of Alternaria isolates tested on whole plants were reflective of results obtained from the detached-leaf assays, although this has not been the case in other studies (Odilbekov et al. 2014). A correlation between field and whole-plant assays with detached-leaf assays was not found in a previous study. It was also determined that a higher level of resistance to infection was exhibited in detached-leaf assays (Odilbekov et al. 2014). In this study, A. arborescens and A. arbusti exhibited increased resistance in the detached-leaf assay. Although detached-leaf assays may not be suitable for assessing field resistance of a cultivar, they can be used to gauge an isolate's aggressiveness. Overall, $A$. arbusti isolates were the least aggressive among the three Alternaria isolates and A. solani was the most aggressive, regardless of assay type. A positive relationship was observed when the AULEC of Alternaria isolates on whole plants was regressed against the AULEC on detached leaves, indicating that the detached-leaf assay has the potential to robustly predict the response of whole plants to infection.

A. arborescens and $A$. arbusti are likely less important pathogens in the field than A. solani, although A. arborescens is an aggressive pathogen on potato when leaves are wounded. This is supported by the increase in mean infection frequency and aggressiveness of $A$. arborescens isolates on nonwounded and wounded tissue. In contrast, whereas $A$. arbusti is capable of infecting wounded potato foliage, the comparatively diminished AULEC suggests that it is not as effective in colonizing host tissue as A. arborescens or A. solani.

A. arbusti on potato may not be a new pathogen. There is extensive morphological plasticity of $A$. arborescens and A. arbusti and they may overlap in morphological characteristics (Simmons 2007). Therefore, it is possible that $A$. arbusti was misidentified as A. alternata in the past. Two key features differentiate A. arbusti from A. arborescens. Young conidial chains of A. arbusti are not branched, although branching can occur on secondary conidiophores and older primary conidiophores (Simmons 1993), and a conidium of A. arbusti typically produces one to five cells at the apical end to form a secondary conidiophore (Simmons 1993).

Alternatively, the pathogenicity of $A$. arbusti on potato may be a result of a newly emerging pathogen due to either an expansion in host range or a change in virulence, possibly through horizontal gene transfer (Stukenbrock and McDonald 2008). Geographically, pear and cherry are grown in close proximity to potato in central Washington, increasing the potential for local adaptation of $A$. arbusti to potato. Horizontal gene transfer of virulence genes between A. arborescens and A. arbusti may be responsible for the ability of potato to serve as a new host and is the proposed mechanism through which $A$. arborescens acquired host-specific toxin genes (Akagi et al. 2009; Hu et al. 2012).

A. arbusti, which has not been previously known to cause disease in potato, was only mildly aggressive in this study, even when wounding had occurred on leaf tissue. This suggests that $A$. arbusti

Table 6. Area under the lesion expansion curve on wounded leaves of Russet cultivars inoculated with three Alternaria spp. ${ }^{\mathrm{a}}$

\begin{tabular}{|c|c|c|c|c|}
\hline Cultivar & Alternaria arborescens & A. arbusti & A. solani & $P$ value \\
\hline Umatilla Russet & $125 \mathrm{a}^{*}$ & $80 \mathrm{a}^{*}$ & $1,488 \mathrm{a}$ & 0.0063 \\
\hline Ranger Russet & $105 a^{*}$ & $44 \mathrm{ab}^{*}$ & $625 \mathrm{ab}$ & 0.019 \\
\hline Norkotah Russet & $142 a^{*}$ & $32 \mathrm{ab}^{*}$ & $604 a b$ & 0.0334 \\
\hline Russet Alturas & $13 \mathrm{a}$ & $3 \mathrm{~b}$ & $43 \mathrm{~b}$ & 0.1104 \\
\hline Russet Burbank & $0 \mathrm{a}^{*}$ & $0 \mathrm{~b}^{*}$ & $135 \mathrm{~b}$ & 0.001 \\
\hline$P$ value & 0.4535 & 0.1679 & 0.1422 & $\ldots$ \\
\hline
\end{tabular}

a Values with the same letters within a column are not significantly different at $P \geq 0.05$. An asterisk $(*)$ indicates that values are significantly different than for A. solani (across a row) at $P<0.05$. 
is a minor pathogen that contributes little to disease symptoms in the field. No pathogenicity studies have been performed using $A$. arbusti to determine whether it is actually a pathogen on pear and cherry or merely a saprophyte. The host range of this fungus needs to be determined to assess potential impacts that it may have on orchards, especially those located in close proximity to potato fields, as in the Pacific Northwest.

\section{Acknowledgments}

We thank M. Pavek, G. Vandemark, and F. Dugan for critical reviews of the manuscript; D. Drader, M. Hubbard, and J. Miller for providing us with potato leaf samples; and the Washington State Potato Commission for partial funding of this study.

\section{Literature Cited}

Akagi, Y., Akamatsu, H., Otani, H., and Kodama, M. 2009. Horizontal chromosome transfer, a mechanism for the evolution and differentiation of a plant pathogenic fungus. Eukaryot. Cell 8:1732-1738.

Andersen, B., and Thrane, U. 1996. Differentiation of Alternaria infectoria and Alternaria alternata based on morphology, metabolite profiles, and cultural characteristics. Can. J. Microbiol. 42:685-689.

Andrew, M., Peever, T., and Pryor, B. 2009. An expanded multilocus phylogeny does not resolve morphological species within the small-spored Alternaria species complex. Mycologia 101:95-109.

Ardestani, S. T., Sharifnabi, B., Zare, R., and Moghadam, A. A. 2010. New Alternaria species associated with potato leaf spot in various potato growing region of Iran. Iran. J. Plant Pathol. 45:83-86.

Blachinski, D., Shtienberg, D., Dinoor, A., Kafkafi, U., Sujkowski, L., Zitter, T., and Fry, W. 1996. Influence of foliar application of nitrogen and potassium on Alternaria diseases in potato, tomato and cotton. Phytoparasitica 24:281-292.

Blodgett, J., and Swart, W. 2002. Infection, colonization, and disease of Amaranthus hybridus leaves by the Alternaria tenuissima group. Plant Dis. 86:1199-1205

Boiteux, L., Reifschneider, F., Fonseca, M., and Buso, J. 1995. Search for sources of early blight (Alternaria solani) field resistance not associated with vegetative late maturity in tetraploid potato germplasm. Euphytica 83:63-70.

Cappellini, R., and Ceponis, M. 1977. Vulnerability of stem-end scars of blueberry fruits to postharvest decays. Phytopathology 67:118-119.

Douglas, D., and Pavek, J. 1972. Screening potatoes for field resistance to early blight. Am. Potato J. 49:1-6.

Droby, S., Dinoor, A., Prusky, D., and Barkaigolan, R. 1984. Pathogenicity of Alternaria alternata on potato in Israel. Phytopathology 74:537-542.

Ellis, J., and Martin, G. 1882. Macrosporium solani E\&M. Am. Nat. 16:1003.

Fry, W. E. 2007. The canon of potato science: 10. late blight and early blight. Potato Res. 50:243-245

Hong, S. G., Cramer, R. A., Lawrence, C. B., and Pryor, B. M. 2005. Alt a 1 allergen homologs from Alternaria and related taxa: Analysis of phylogenetic content and secondary structure. Fungal Genet. Biol. 42:119-129.

Hu, J., Chen, C., Peever, T., Dang, H., Lawrence, C., and Mitchell, T. 2012. Genomic characterization of the conditionally dispensable chromosome in Alternaria arborescens provides evidence for horizontal gene transfer. BMC Genomics 13:171.

Johansen, R. H., Farnsworht, B., Nelson, D. C., Secor, G. A., Gudmestad, N., and Orr, P. H. 1988. Russet Norkotah: A new russet-skinned potato cultivar with wide adaptation. Am. Potato J. 65:597-604.

Johanson, A., and Thurston, H. 1990. The effect of cultivar maturity on the resistance of potatoes to early blight caused by Alternaria solani. Am. Potato J. 67:615-623.

Kirk, W., and Wharton, P. 2012. Brown leaf spot. Mich. State Ext. Bull. E-3182. Department of Plant, Soil and Microbial Science, Michigan State University.

Kumar, C. S. K. V., and Rao, A. S. 1979. Production of phytotoxic substances by Alternaria triticina. Can. J. Bot. 57:1255-1258.

Lawrence, D. P., Gannibal, P. B., Peever, T. L., and Pryor, B. M. 2013. The sections of Alternaria: Formalizing species-group concepts. Mycologia 105: $530-546$.

Logrieco, A., Bottalico, A., Solfrizzo, M., and Mule, G. 1990. Incidence of Alternaria species in grains from Mediterranean countries and their ability to produce mycotoxins. Mycologia 82:501-505.

MacKenzie, D. 1981. Association of potato early blight, nitrogen fertilizer rate, and potato yield. Plant Dis. 65:575-577.
Mosley, A. R., James, S. R., Hane, D. C., Rykbost, K. A., Shock, C. C., Charlton, B. A., Pavek, J. J., Love, S. L., Corisini, D. L., and Thornton, R. E. 2000 Umatilla Russet: A full season long russet for processing and fresh market use. Am. J. Potato Res. 77:83-87.

Nolte, P. 2008. Brown spot and black pit of potato: The other early blight. Am. Veg. Grow. 56:32-33.

Novy, R. G., Corsini, D. L., Love, S. L., Pavek, J., Mosley, A. R., James, S. R., Hane, D. C., Shock, C. C., Rykbost, K. A., and Brown, C. R. 2003. Alturas: A multi-purpose russet potato cultivar with high yield and specific gravity. Am. J. Potato Res. 80:295-301.

Odilbekov, F., Carlson-Nilsson, U., and Liljeroth, E. 2014. Phenotyping early blight resistance in potato cultivars and breeding clones. Euphytica 197:87-97.

Olanya, O. M., Honeycutt, C. W., Larkin, R. P., Griffin, T. S., He, Z., and Halloran, J. M. 2009. The effect of cropping systems and irrigation management on development of potato early blight. J. Gen. Plant Pathol. 75:267-275.

Pavek, J. J., Corsini, D. L., Love, S. L., Hane, D. C., Holm, D. G., Iritani, W. M., James, S. R., Martin, M. W., Mosley, A. R., Ojala, J. C., Stanger, C. E., and Thornton, R. E. 1992. Ranger Russet: A long Russet potato variety for processing and fresh market with improved quality, disease resistance, and yield. Am. J. Potato Res. 69:483-488.

Peever, T., Su, G., Carpenter-Boggs, L., and Timmer, L. 2004. Molecular systematics of citrus-associated Alternaria species. Mycologia 96:119-134.

Pelletier, J., and Fry, W. 1989. Characterization of resistance to early blight in three potato cultivars: Incubation period, lesion expansion rate, and spore production. Phytopathology 79:511-517.

Pryor, B. M., and Gilbertson, R. L. 2000. Molecular phylogenetic relationships amongst Alternaria species and related fungi based upon analysis of nuclear ITS and mt SSU rDNA sequences. Mycol. Res. 104:1312-1321.

Rodrigues, T., Berbee, M., Simmons, E., Cardoso, C., Reis, A., Maffia, L., and Mizubuti, E. 2010. First report of Alternaria tomatophila and A. grandis causing early blight on tomato and potato in Brazil. New Dis. Rep. 22:28.

Dita Rodriguez, M. A., Brommonschenkel, S. H., Matsuoka, K., and Mizubuti, E. S. G. 2006. Components of resistance to early blight in four potato cultivars: Effect of leaf position. J. Phytopathol. 154:230-235.

Rotem, J. 1994. The Genus Alternaria: Biology, Epidemiology, and Pathogenicity. American Phytopathological Society, St. Paul, MN.

Rykbost, K. A., Carlson, H. L., and Voss, R. 1990. Potato varieties: An introduction to variety characteristics, management, and performance in the Klamath Basin. Spec. Rep. 859. Oregon State University.

Shaner, G., and Finney, R. 1977. The effect of nitrogen fertilization on the expression of slow-mildewing resistance in Knox wheat. Phytopathology 67:1051-1056.

Sharratt, B., and Lauer, D. 2006. Particulate matter concentration and air quality affected by windblown dust in the Columbia Plateau. J. Environ. Qual. 35: 2011-2016.

Shtienberg, D., Blachinsky, D., Kremer, Y., Ben-Hador, G., and Dinoor, A. 1995. Integration of genotype and age-related resistances to reduce fungicide use in management of Alternaria diseases of cotton and potato. Phytopathology 85 995-1002.

Simmons, E. 1992. Alternaria taxonomy: Current status, viewpoint, and challenge. Pages 1-36 in: Alternaria: Biology, Plant Diseases, and Metabolites. J. Chelkowski and A. Visconti, eds. Elsevier Science Publishers, New York.

Simmons, E. 1993. Alternaria themes and variations (63-72). Mycotaxon 48 91-107.

Simmons, E. G. 2007. Alternaria: An Identification Manual. CBS Fungal Biodiversity Centre, Utrecht, The Netherlands.

Stukenbrock, E. H., and McDonald, B. A. 2008. The origins of plant pathogens in agro-ecosystems. Annu. Rev. Phytopathol. 46:75-100.

Thomma, B. P. 2003. Alternaria spp.: From general saprophyte to specific parasite Mol. Plant Pathol. 4:225-236.

Tymon, L., and Johnson, D. 2011. Prevalence and aggressiveness of Alternaria solani and A. alternata on potato in the Columbia Basin of the Pacific Northwest. (Abstr.) Phytopathology 101:S180.

Tymon, L., Peever, T. L., and Johnson, D. A. 2015. Identification and enumeration of small-spored Alternaria species associated with potato in the U.S. Northwest. Plant Dis. 100:465-472.

van der Waals, J. E., Pitsi, B., Marais, C., and Wairuri, C. K. 2011. First report of Alternaria alternata causing leaf blight of potatoes in South Africa. Plant Dis. 95:363

Wharton, P., and Kirk, W. 2007. Early blight. Mich. State Ext. Bull. E-2991. Department of Plant, Soil and Microbial Science, Michigan State University, East Lansing. 